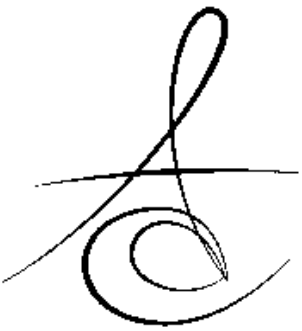

\title{
MENSTRUAL DÖNEMDE VE ÖNCESİNDE TEMPOROMANDİBULAR EKLEM, BAŞ- BOYUN, YÜZ-KULAK BÖLGESİ AĞRILARININ GÖRÜLME SIKLIĞININ ARAŞTIRILMASI: PİLOT ÇALIŞMA
}

\section{THE INCIDENCE OF PAIN IN THE TEMPOROMANDIBULAR JOINT, HEAD-NECK REGION AND FACE-EAR REGION BEFORE AND DURING MENSTRUAL PERIOD: A PILOT STUDY}

\author{
Dr. Öğr. Üy. C. Neslihan EROĞLU* $\quad$ Dr. Öğr. Üy. Serap KESKİN TUNÇ* \\ Öğr Gör Sadi ELASAN**
}

Makale Kodu/Article code: 2996

Makale Gönderilme tarihi: 17.08 .2016

Kabul Tarihi: 28.12.2016

\section{öz}

Amaç: Kadınlarda menstrual dönemde östrojen seviyesinin düşmesine bağlı olarak ağrı hassasiyetinde değişimler olduğu savunulmaktadır. Bu çalışmada menstrual dönemi ve öncesinde temporomandibular eklem (TME), baş-boyun, yüz-kulak ağrılarının görülme sıklığının araştırılması amaçlanmıştır.

Gereç ve Yöntem: Menstrual periotları sorunsuz ve düzenli olan kadın bireyler çalışmaya dahil edildi. Hastalar, menstrual dönemde olan ve olmayan olarak iki gruba ayrıldı. Tüm hastalara TME hastalıkları için TMR/ATK (Temporomandibular Rahatsızlık/ Araştırma Teşhis Kriterleri) muayene anket formu uygulandı. Ek olarak TME, yüz-kulak, baş-boyun bölgesinde ağrı varlığı değerlendirildi.

Bulgular: Gruplar arasında istatistiksel olarak anlamlı bir farklııı bulunmadı. Tüm hastaların \% 50'si tek bölge ağrısı bildirmişlerdir. Hastaların \% 23.5'inde TME ağrısı mevcuttur. TME şikayeti bulunan hastaların \% 73.5'i menstrual dönemde değildir.

Sonuç: Kadınlar menstruasyon döneminde daha çok baş-boyun ağrılarından, menstrual dönem öncesinde TME ağrılarından etkilenmektedirler.

Anahtar Kelimeler: Menstruasyon, Tempromandibular eklem, baş-boyun, yüz, kulak, ağrı

\section{ABSTRACT}

Aim: It is defended that pain sensation changes during menstrual period due to decreased estrogen level. The present study aimed to investigate the incidence of pain in the temporomandibular joint (TMJ), head-neck region and face-ear region before and during menstrual period.

Materials and Methods: Female subjects with regular and problem-free menstrual period were enrolled in the study. Patients were grouped as the women who were in the menstrual period and the women who were not. All patients completed RDC / TMD (Research Diagnostic Criteria for Temporomandibular Disorder) questionnaire form for the symptoms of TMJ disorders. In addition, presence of pain in the $\mathrm{TMJ}$, head-neck region and face-ear region was also assessed.

Results: There was no statistically significant difference between the groups. Half of (50\%) overall patients reported pain in a single region. TMJ pain was present in $23.5 \%$ of the patients. Of the patients having TMJ pain, $73.5 \%$ were not in the menstrual period.

Conclusion: Women usually suffer from head-neck pain during menstrual period but from TMJ pain before menstrual period.

Keywords: Menstruation, temporomandibular joint, head-neck, face, ear, pain.

\footnotetext{
*Yüzüncü Yıl Üniversitesi, Diş Hekimliği Fakültesi, Ağız, Diş, Çene Cerrahisi AD

**üzüncü Yıl Üniversitesi, Tıp Fakültesi, Biyoistatistik AD
} 


\section{GİRIŞ̧}

Cinsiyet farklılığı ve menstrual siklusun ağrı üzerindeki etkisi bir çok araştırmacının dikkatini çeken ve literatürde halen kesin bir sonuca ulaşılamayan konulardan biridir. ${ }^{1-5}$ Özellikle premenopozal dönemde kadınlarda ovarian hormonlardaki değişimler nedeniyle ağrı hassasiyetinin erkeklere göre daha yüksek olduğu ve kas-iskelet sisteminin bu değişimlerden etkilendiği savunulmaktadır.,6,7 Menstrüasyon, hipotalamus, hipofiz ve yumurtalıklar tarafından üretilen hormonların etkileşimlerine yanıt olarak, uterus yüzeyinin düzenli, düzensiz dökülmesidir. Menstrual döngü iki aşamaya ayrılabilir: foliküler veya proliferatif faz ve luteal veya sekretuar faz. Menstrual siklusun uzunluğu, bir menstrual kanamasının ilk günü ile bir sonraki menstrual kanamanın başlangıcı olarak tanımlanmaktadır. ${ }^{8}$ Kadınlarda menstruasyon dönemi semptomları arasın da temporomandibular eklem (TME) ağrıları, baş ağrıları ve diğer bölge ağrıları sayılmaktadır. Genellikle TME ağrıları, migren/baş ağrısı, ${ }^{9,10}$ boyun, ${ }^{11,12}$ bel, ${ }^{13}$ diğer eklem ağrıları ${ }^{14}$ ile birlikte ortaya çıkmaktadırlar. Bunların içinde de boyun ve migren/baş ağrısı TME ağrıları ile birlikte en sık görülen ağrılar olarak rapor edilmiştir. $^{15}$

Literatürde kadınlarda TME, baş-boyun ve yüzkulak bölgesi ağrılarının birlikte ve ayrı ayrı görülme sıklığının menstruasyon dönemi ile ilişkisini araştıran yayın sayısı çok azdır. Bu çalışmada kadınlarda menstruasyon dönemi dışında ve menstrual dönemde TME, baş-boyun, yüz-kulak bölgesi ağrılarının insidansının araştırıması amaçlanmıştır.

\section{GEREÇ VE YÖNTEM}

Çalışmaya herhangi bir sistemik rahatsızlığı olmayan, menstruasyon siklusları düzenli olan ve oral kontraseptif kullanmayan, ağrı şikayeti olan, 68 genç kadın dahil edilmiştir. Tüm bireylere TME hastalıklarının klinik değerlendirmesi için 1992 yılında Dworkin ve Le Reche tarafından belirlenen Temporomandibular Rahatsızlıklar /Araştırma Teşhis Kriterleri (TMR/ATK) (Eksen-I) uygulanmıştır. ${ }^{16} \mathrm{Bu}$ ankete ek olarak daha önce geçirilen herhangi bir iltihabi süreç olmaksızın TME, baş-boyun, yüz-kulak bölgesi ağrısı olup olmadığı ve menstrual dönemde olup olmadıkları sorulmuştur. Hastalar menstrual dönemde olan ve olmayanlar olarak iki gruba ayrılmıştır. Çalışma için YYÜ Tıp Fakültesi Klinik Araştırmalar Etik Kurulundan onay alınmıştır.

\section{BULGULAR}

Hastaların yaş ortalaması $23.7 \pm 3.1$ 'dir. Çalışmaya katılanların \% 20.6'sı evli $(n=14)$, \% 79.4'ü bekar $(n=54), \% 5.9^{\prime} u$ ilköğretim mezunu $(n=4), \% 58.8^{\prime} i$ lise mezunu $(n=40), \% 35.3$ 'ü üniversite mezundur $(n=24)$. Çalışmaya katılan hastalar TME, baş-boyun ve yüz-kulak bölgelerinden en az birinde ağrı şikayetine sahiptir. Menstruasyon dönemindeki hastaların TME ağrılarının VAS ortalaması 1.1, menstruasyon döneminde olmayan hastaların TME ağrılarının VAS ortalaması 2.3 olarak saptanmıştır. Hastaların \% 50'si araştırılan bölgelerden sadece biri için ağrı bildirmişlerdir. TMR/ATK Eksen I'e göre menstruasyon döneminde olan ve olmayanlar için TME hastalığı olan kişi sayısı Tablo 1'de gösterilmiştir. TME şikayeti bulunan hastaların \% 73.5'i menstrual dönemde değildir. Menstrual dönem ve bölgelere göre ağrı bildiren hasta sayısı Tablo 2'de gösterilmiştir. Tüm hastaların \% 23.5'inde TME ağrısı mevcuttur. Hastaların \% 88.2'si baş-boyun ağrısından tek başına veya diğer bölge ağrılarıyla birlikte bildirmişlerdir. Tek veya diğer bölge ağrılarıyla birlikte yüz-kulak ağrı şikayeti olanların \% 87.5'i menstrual dönemde değildir. Menstrual dönemdeki hastaların da \% 78' i sadece baş-boyun ağrısı, \% 22'si ise diğer bölge ağrılarıyla birlikte baş-boyun ağrısı tarif etmişlerdir. Fakat gruplar arasında TME, baş-boyun ve yüz-kulak ağrısı bakımından istatistiki olarak anlamlı bir farklılık bulunmamıştır.

Tablo 1. TMR/ATK Eksen-I'e göre menstrual dönem olan ve olmayan TME hastalığı bulunan hasta sayısı

\begin{tabular}{lcc}
\hline TME hastalığı & $\begin{array}{c}\text { Menstrual Dönem } \\
(+)\end{array}$ & $\begin{array}{c}\text { Menstrual Dönem } \\
(-)\end{array}$ \\
\hline Var & $n$ & $n$ \\
\hline Yok & 4 & 16 \\
\hline
\end{tabular}

Tablo 2. Bölgesel ağrı şikayetine göre menstrual dönemde olan ve olmayan hasta sayıları

\begin{tabular}{lcc}
\hline Ağrı & $\begin{array}{c}\text { Menstrual } \\
\text { Dönem (+) }\end{array}$ & $\begin{array}{c}\text { Menstrual } \\
\text { Dönem (-) }\end{array}$ \\
\hline Yüz-Kulak & $n$ & $n$ \\
Yüz-Kulak, Baş-boyun & 0 & 2 \\
Yüz-Kulak, Baş-boyun, TME & 0 & 6 \\
Baş-boyun & 2 & 6 \\
Baş-boyun, TME & 14 & 26 \\
TME & 2 & 4 \\
\hline Toplam & 0 & 6 \\
\hline
\end{tabular}


TMR/ATK Eksen-I'e göre menstrual dönemde olanların \% 11.1'inde artralji, \% 22.2'sinde Ia myofascial ağrı, \% 11.1'inde tek taraflı redüksiyonlu disk deplasmanı vardır. Menstrual dönemde olmayanların \% 4'ünde artralji, \%12'sinde Ia myofasial ağrı, \% 14 'ünde tek taraflı redüksiyonlu disk deplasmanı ve \% 1 'inde çift taraflı redüksiyonlu disk deplasmanı vardır.

\section{TARTIŞMA}

$\mathrm{Bu}$ pilot çalışmanın sonucunda kadınlarda menstrual dönemde baş-boyun ve TME ağrılarında istatistiksel olarak anlamlı bir fark bulunamamış olsa da menstrual dönemdeki hastaların daha çok başboyun ağrısından şikayetçi olduğu tespit edilmiştir. Menstruasyon döneminde olmayan kadınlarda ise TME ağrısı daha çok gözlenmiştir.

Yapılan çalışmalarda kadınlarda farklı bölge ağrılarının birlikte görülme oranı erkeklere göre daha fazla olarak rapor edilmiştir. ${ }^{17,18}$ Çalışmamızda kadın hastalarda yakın bölge ağrıları değerlendirilmiş olup, araştırılan bölgelerde ortak ağrı bildiren hasta sayısı ile sadece tek bir bölgeden şikayeti olan hasta sayısı eşittir.

TME disfonksiyonuna bağlı gelişen ağrı ve migren tipi baş ağrıları görülme sıklığı benzer olan ağrılar olmasıyla birlikte hormonal faktörler bu ağrılarda cinsiyetler arasında farklıık oluşturmaktadır. ${ }^{19,20}$ LeResche ve ark.; östrojen seviyesinin düşmesinin özellikle TME rahatsızlıklarının patofizyolojisinde rol oynadığını rapor ederken, ${ }^{21}$ Dao ve ark da özellikle myofasial ağrı sendromunda üreme hormonlarının etkisinin olduğunu belirtmiştir. ${ }^{22}$ Kadınlarda erken folikuler faz ve geç luteal fazda hissedilen ağrının hafiften- orta şiddete kadar değişen derecelerde ağrı hassasiyetinde artmaların gözlendiği dönemler olduğunu rapor eden çalışmalar bulunmaktadır. ${ }^{1-5} \mathrm{Biz}$ bu çalışmada menstrual siklusun olup olmadığı dışında hastaların bu fazlardan hangisinde olduğunu araştırmadık. Bu bakımdan çalışma sonuçlarımızda menstrual dönemde olmayan hastaların hissettikleri ağrılarda içinde bulundukları faz dönemlerinin de bir etkisi olabilir. Çalışmanın limitasyonu olarak görülebilecek bir durum olmasına karşın tüm fazlardaki ağrı değerlendirmesi pratik olarak zordur. Ciddi bir hasta kooperasyonu, jinekolojik olarak ultrasonografi ve hematolojik tetkiklerin gerekliliği göz önünde bulundurulmalıdır. Bunun dışında TME ağrıları, fasial ağrı, çene kasları veya kulak önündeki eklem ağrısı olarak tanımlanan bir durum olduğundan 23,24 hastalar TME ağrılarını yakın bölge olan baş- boyun ve yüz-kulak ağrısı olarak tanımlamış olabilir. Baş- boyun kaslarında oluşan bir ağrı TME fonksiyonlarını etkileyebilmektedir. ${ }^{25}$ Dolayısıyla bu bölgelerin ağrıları veya semptomlarının araştırımasında tam bir sınır çizmek mümkün olamamaktadır.

Literatürde dökümante edilen çalışma sayısının oldukça yetersiz olmasından yakınılırken, menstrual döngüde östrojen, progesteron ve testosteron hormonlarının arasındaki ilişki ve düzeylerindeki değişikliğin ağrı için potansiyel faktörler olarak araştırılmasının daha objektif sonuçlara götürebileceğinden bahsedilmektedir.6,26

Östrojen seviyesindeki azalma veya ani düşüşlerde ağrı hassasiyeti artmaktadır. ${ }^{27}$ Çalışmamızda da menstrual dönemde östrojen seviyesi düştüğü için menstruasyon dönemindeki hastalarda baş-boyun ağrıları daha fazla gözlenmiştir. Diğer taraftan yüzkulak ağrıları daha çok menstruasyon dönemi olmayanlarda ve diğer bölge ağrılarıyla birlikte tarif edilmiştir. Menstruasyonla beraber östrojen seviyesinin düşmesiyle ilişkili olarak, orofasial ağrılar üzerine yapılan bir çalışmada menstruasyon dönemindeki hastalarda hormonlara bağlı orofasial ağrı semptomlarının daha çok görüldüğü tespit edilmiştir. Östrojen seviyesinin azaldığı durumlarda orofasial ağrı açısından da artmış bir risk söz konusudur. ${ }^{28}$

Baş ağrısı menstruasyon dönemi semptomlarından biri olarak sayılmaktadır ve menstrual dönemde kadınlarda baş ağrılarının görülme sıklığının \% 10 olduğu bildirilmiştir. ${ }^{29,30}$ Migren, baş ağrısı kategorisinde en sık rastlanan form olduğu için yapılan çalışmalar daha çok migren üzerinedir. ${ }^{31}$ Doğurganlık çağındaki kadınlarda migren tipi baş ağrılarının sık görüldüğü sonucunu destekleyen çalışmalar mevcuttur. ${ }^{32,33}$ Fakat migrenin stres kaynaklı olabileceği ve premenstrual dönemlerde strese daha duyarlı olunabileceği için menstruasyondan daha çok premenstrual dönemde gözlendiğini belirten çalışmalar da bulunmaktadır. ${ }^{34}$

Balter ve ark'nın kronik boyun ağrısına sahip kadınlarda menstrual periyodun ağrı şiddetinde bir değişime yol açıp açmadığının araştırıldığı çalışmada, menstrual periyottaki ağrı artışının klinik olarak önemli bir seviyede olmadığı gözlenmiştir. ${ }^{6}$ Çalışmada da her iki grupta da en çok ağrı bildirilen bölge baş-boyun bölgesidir. 
Çalışmamızın sınırlarından bir diğeri ise şimdilik bir pilot çalışma olduğundan çalışılan örnek sayısının az olmasıdır. Örnek sayısı artırıldığında istatistiği destekleyecek sonuçlara ulaşılabileceğini düşünmekteyiz. Bu tip araştırmalarda ağrı parametresinin etkilendiği birçok faktör olduğu göz önüne alındığında (eğitim, yaş, medeni durum, sosyo-ekonomik düzey vs gibi $^{35}$ örnek seçiminde homojen geniş bir örnek grubu oluşturulması daha ideal olabilir.

Sonuç olarak, bu çalışmanın sınırları içinde menstruasyon döngüsü devam eden kadınlarda TME, baş-boyun veya yüz-kulak ağrısı tek başına veya diğer bölge ağrılarıyla birlikte görülme oranı oldukça yüksektir. Menstrual periyot içindeyken bu ağrılardan baş-boyun ağrıları en fazla tek başına görülen ağıı tipi olarak karşımıza çıkmışıı. TME ağıısı, menstrual periyota özgü bir semptom olarak görülmemiş olup bireysel tolerans, daha önceden eklem hastalığının varlığı ve hormon döngüsünün hangi aşamasında farklılık gösterdiği gibi faktörlerin etkisi yapılacak yeni çalışmalarda değerlendirilebilir. Ayrıca hastaların eklem bölgesine komşu tüm dokuların ağrısını da eklem ağrısı gibi ya da eklem ağrısını komşu bölge ağrılarıyla birlikte tarif edebileceği unutulmamalıdır.

Cennet Neslihan Eroğlu, ORCID ID: 0000-0002-0856-7998 Serap Keskin Tunç: , ORCID ID: 000-0001-5439-6598 Sadi Elasan, ORCID ID: 000-0002-3149-6462

\section{KAYNAKLAR}

1. Cairns BE, Gazerani P. Sex-related differences in pain. Maturitas 2009;63:292-6.

2. Fillingim RB, Ness TJ. Sex-related hormonal influences on pain and analgesic responses. Neurosci Biobehav Rev 2000;24:485-501.

3. Martin VT. Ovarian hormones and pain response: a review of clinical and basic science studies. Gend Med 2009;6:168-92.

4. Riley JL 3rd, Robinson ME, Wise EA, Price DD. A meta-analytic review of pain perception across the menstrual cycle. Pain 1999;8:225-35.

5. Sherman JJ, LeResche L. Does experimental pain response vary across the menstrual cycle? A methodological review. Am J Physiol Regul Integr Comp Physiol 2006;291:R245-56.
6. Balter JE, Molner JL, Kohrt WM, Maluf KS. Mechanical pain sensitivity and the severity of chronic neck pain and disability are not modulated across the menstrual cycle. J Pain 2013;14:1450-9.

7. Salaffi F, De Angelis R, Grassi W. Prevalence of musculoskeletal conditions in an Italian population sample: results of a regional community-based study. I. The MAPPING study. Clin Exp Rheumatol 2005;23:819-28.

8. Reed BG, Carr BR. The Normal Menstrual Cycle and the Control of Ovulation.In: De Groot $L$, Chrousos G, Dungan K, Feingold KR, Grossman A, Hershman JM, Koch C, Korbonits M, McLachlan R, New M, Purnell J, Rebar R, Singer F, Vinik A, editors. Endotext [Internet]. South Dartmouth (MA): MDText.com, Inc; 2000-.2015 May 22.

9. Ciancaglini R, Radaelli $G$. The relationship between headache and symptoms of temporomandibular disorder in the general population. J Dent 2001;29:93-8.

10. Rantala MA, Ahlberg J, Suvinen TI, Nissinen M, Lindholm $H$, Savolainen $A$, Könönen $M$. Temporomandibular joint related painless symptoms, orofacial pain, neck pain, headache, and psychosocial factors among non-patients. Acta Odontol Scand 2003;61:217-22.

11. Wänman A. The relationship between muscle tenderness and craniomandibular disorders: a study of 35-year-olds from the general population. J Orofac Pain 1995;9:235-43.

12. De Laat A, Meuleman H, Stevens A, Verbeke G. Correlation between cervical spine and temporomandibular disorders. Clin Oral Investig 1998;2:54-7.

13. Wiesinger $B$, Malker $H$, Englund $E$, Wänman $A$. Back pain in relation to musculoskeletal disorders in the jaw-face: a matched case-control study. Pain 2007;131:311-9.

14. Wolfe F, Katz RS, Michaud K. Jaw pain: its prevalence and meaning in patients with rheumatoid arthritis, osteoarthritis, and fibromyalgia. J Rheumatol 2005;32:2421-8.

15. Kim TY, Shin JS, Lee J, Lee YJ, Kim MR, Ahn YJ, Park KB, Hwang DS, Ha IH. Gender Difference in Associations between Chronic Temporomandibular Disorders and General Quality of Life in Koreans: A Cross-Sectional Study. PLoS One 2015;10: e0145002.

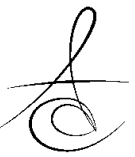


16. Dworkin SF, LeResche L. Research diagnostic criteria for temporomandibular disorders: review, criteria, examinations, and specifications, critique. J Craniomandib Disord 1992;6:301-355.

17. Unruh AM. Gender variations in clinical pain experience. Pain 1996;65:123-67.

18. Berkley KJ. Sex differences in pain. Behav Brain Sci 1997;20:371-80; discussion 435-513.

19. Stewart WF, Lipton RB, Celentano DD, Reed ML. Prevalence of migraine headache in the United States. Relation to age, income, race, and other sociodemographic factors. JAMA 1992;267:64-9.

20. Ayalı A, Ramoğlu S. Kuzey Kıbrıs'ta diş hekimliği fakültesi öğrencilerinde temporomandibular eklem disfonksiyonunun prevalansı ve şiddetinin araştırılması. Atatürk Üniv Diş Hek Fak Derg 2014;24:367-72.

21. LeResche L, Saunders K, Von Korff MR, Barlow W, Dworkin SF. Use of exogenous hormones and risk of temporomandibular disorder pain. Pain 1997;69:153-60.

22. Dao TT, Knight K, Ton-That V. Modulation of myofascial pain by the reproductive hormones: a preliminary report. J Prosthet Dent 1998;79:66370.

23. Nilsson IM, List T, Drangsholt $M$. The reliability and validity of self-reported temporomandibular disorder pain in adolescents. J Orofac Pain 2006;20:138-44.

24. Pinelli C, de Castro Monteiro Loffredo L. Reproducibility and validity of self-perceived oral health conditions. Clin Oral Investig 2007;11:4317.

25. Ezirganlı Ş, Kara Mİ, Küçük D, Özan F, Polat S. Erişkin Türk toplumunda maksimum ağız açıklığı miktarı ve temporomandibular eklem bozuklukları ile ilişkisinin araştırılması. Atatürk Üniv Diş Hek Fak Derg 2013;21:57-62.

26. Vincent K, Warnaby C, Stagg CJ, Moore J, Kennedy S, Tracey I. Brain imaging reveals that engagement of descending inhibitory pain pathways in healthy women in a low endogenous estradiol state varies with testosterone. Pain 2013;154:515-24.

27. LeResche L, Mancl L, Sherman JJ, Gandara B, Dworkin SF. Changes in temporomandibular pain and other symptoms across the menstrual cycle. Pain 2003; 106:253-61.
28. Macfarlane TV, Blinkhorn AS, Davies RM, Kincey J, Worthington HV. Association between female hormonal factors and oro-facial pain: study in the community. Pain 2002;97:5-10.

29. Doty E, Attaran M. Managing primary dysmenorrhea. J Pediatr Adolesc Gynecol 2006; 19:341-4.

30. Miziara L, Bigal ME, Bordini CA, Speciali JG. Menstrual headache: semiological study in 100 cases. Arq Neuropsiquiatr 2003;61:596-600.

31. Shaik MM, Gan SH. Vitamin supplementation as possible prophylactic treatment against migraine with aura and menstrual migraine. Biomed Res Int. 2015;2015:469529. doi: 10.1155/2015/469529.

32. Graziottin A, Zanello PP. Menstruation, inflammation and comorbidities: implications for woman health. Minerva Ginecol 2015;67:21-34.

33. MacGregor EA. Migraine Management During Menstruation and Menopause. Continuum (Minneap Minn) 2015;21:990-1003.

34. Parashar R, Bhalla $P$, Rai NK, Pakhare A, Babbar R. Migraine: is it related to hormonal disturbances or stress?. Int J Womens Health 2014;24;6:921-5.

35. Grøholt EK, Stigum H, Nordhagen R, Köhler L. Recurrent pain in children, socio-economic factors and accumulation in families. Eur J Epidemiol 2003;18:965-75.

\section{Yazışma Adresi}

Dr. Öğr . Üyesi Cennet Neslihan EROĞLU

Yüzüncü Yıl Üniversitesi Diş Hekimliği Fakültesi Ağız, Diş ve Çene Cerrahisi AD Kampüs/VAN e-mail: neslihanakca2003@yahoo.com 